\title{
Development of antifungal formulations and their evaluation against root rot disease of mulberry
}

P.M. Pratheesh Kumar

Central Sericultural Research and Training Institute, Mysore (Karnataka) India

\section{ARITCLE INFO}

Received : 22.08 .2019

Revised : 11.09 .2019

Accepted : 25.09.2019

KEY WORDS :

Antifungal formulations, Field

evaluation, Mulberry, Root rot disease

Corresponding author:

Email : pratheesh.pm@gmail.com

\begin{abstract}
Mulberry (Morus sp.) cultivated throughout India for rearing of silkworm (Bombyx mori L.). Root rot caused by a group of fungi is a severe threat for mulberry (Morus spp.) leaf production, especially in southern states of India due to large scale mortality and enormous crop loss. Fungi such as Fusarium solani, Fusarium oxysporum, Rhizoctonia bataticola and Botryodiplodia theobromae are frequently isolated from the infected roots. Few control measures recommended could not sustain due to inconsistent results. In this perspective, studies were conducted to develop a broad spectrum formulation to contain the disease. Several plant products, synthetic fungicides and chemicals were screened for antifungal activities in vitro in solid and broth media using poisoned food technique. Five formulations were made using selected antifungal components and tested against root rot disease under artificial simulation. All the formulations significantly $(\mathrm{P}<0.01)$ reduced wilting and rotting compared with untreated control as well as plants treated existing control measure. Highest control of wilting $(88.20 \%)$ and rotting (88.05\%) was showed by formulation F-1, followed by F-2 and F-4 compared with untreated control. The highly effective formulation (F-1) was further tested in the hotspot areas of Karnataka showed revival of plants with range of 67-86 per cent. This eco-friendly formulation could be used for control of root rot disease of mulberry.
\end{abstract}

How to view point the article : Pratheesh Kumar, P.M. (2019). Development of antifungal formulations and their evaluation against root rot disease of mulberry. Internat. J. Plant Protec., 12(2) : 166-171, DOI : 10.15740/HAS/IJPP/12.2/166-171, Copyright@ 2019: Hind Agri-Horticultural Society. 